\title{
O GRUPO BANCO MUNDIAL: ORIGEM, FUNCIONAMENTO E A INFLUÊNCIA DO DESENVOLVIMENTO SUSTENTÁVEL EM SUAS POLÍTICAS ${ }^{1}$
}

Alfredo Eric Romminger ${ }^{2}$

\section{Resumo}

Este artigo realiza um estudo sobre as origens do Grupo Banco Mundial e sua evolução como instituição de fomento ao crescimento econômico. Além disso, investiga o funcionamento do Banco, como ele atua na promoção do desenvolvimento e como suas estratégias desenvolvimentistas mudaram ao longo dos anos. Nesse sentido, este trabalho analisa as ações do Banco sob a ótica do Desenvolvimento Sustentável, revendo os conceitos do Grupo sobre desenvolvimento econômico e concluindo que as transformações ocorridas nessa instituição adaptaram-se as mudanças ocorridas na percepção sobre a influência do meio ambiente na continuidade do desenvolvimento mundial.

\footnotetext{
${ }^{1}$ Artigo baseado no Capítulo 3 da Monografia Final, para o Curso de Relações Internacionais do Uniceub, de título "O Banco Mundial e o Desenvolvimento Sustentável: a ação do Banco Mundial no financiamento do setor energético", de mesma autoria.

${ }^{2}$ Graduando do $2^{\circ}$ Semestre de 2003 no Curso de Relações Internacionais do UniCEUB e aluno do $5^{\circ}$ período de Graduação em Ciências Econômicas da UnB. O autor agradece a orientação de Marden Barbosa e a paciência e motivação oferecidas pelo editor Marco Antônio Silva na elaboração deste artigo, isentando-os, todavia, de qualquer responsabilidade sobre o aqui exposto.
}

Universitas - Relações Int., Brasília, v. 2, n.1, p. 269-288, jan./jun. 2004 


\begin{abstract}
This article realizes a study about the origin and evolution of the World Bank Group as an institution of economic growth fomentation. It also investigates how the Bank works and how it acts in the promotion of the development and its strategies changed along the years. Therefore, this essay analyses the actions of the Bank under the optic of the sustainable development, reviewing the concepts of the economic development of the Group and concluding that the transformations occurred in this institution adapted to the changes occurred in the perception over the influence of the environment on the continuity of the world development.
\end{abstract}

\title{
1. Introdução
}

Promover o desenvolvimento e reduzir a pobreza é o sonho de grande parte da população mundial. No ano de 2000, $55,7 \%$ da população das regiões não desenvolvidas ${ }^{3}$ vivia com uma renda diária abaixo de US\$2,15, segundo dados do Banco Mundial (WORLD BANK, 2003a). Países cuja população vivem em tais condições, não têm como se tornarem desenvolvidos sozinhos. KALECKI (1977:136) identifica que o principal fator gerador do subdesenvolvimento é a incapacidade dos países mais pobres em aumentarem os investimentos internos consideravelmente, a fim de aumentar sua capacidade produtiva.

Assim, a adoção de algumas políticas desenvolvimentistas podem ser caras ou inviáveis para um país, especialmente para os Países Menos Desenvolvidos (PMDs) ou para os Países em Desenvolvimento (PEDs). Para auxiliar esses países, o Sistema Financeiro Internacional (SFI) criou instituições específicas que buscam oferecer crédito a custos mais baixos a fim de promover o desenvolvimento. Mas na atualidade, a situação tornou-se muito mais complexa do que apenas financiar o crescimento econômico, diversos

\footnotetext{
${ }^{3}$ Tal informação diz respeito às populações da Ásia, América Latina, África e Europa Oriental.
}

Universitas - Relações Int., Brasília, v. 2, n.1, p. 269-288, jan./jun. 2004 
fatores influenciam a atuação desses empréstimos, fatores como os sociais ou ambientais.

Desse modo, neste artigo serão estudadas as instituições do Sistema Financeiro Internacional que surgiram com a Conferência de Bretton Woods, de 1944, bem como a influência do Desenvolvimento Sustentável sobre os financiamentos dessas instituições, como uma nova perspectiva para a promoção do crescimento econômico e eliminação da pobreza mundial. Para este trabalho, dentre as Instituições de Bretton Woods, tem maior importância à atuação do Grupo Banco Mundial, por ser o Banco Internacional de Fomento de maior presença global, de modo que esta pesquisa estará focada principalmente nessa instituição.

\section{As Instituições de Bretton Woods}

Em SALVATORE (2000:430), tem-se que o Sistema Financeiro Internacional representa os costumes, instrumentos e organizações que visam regulamentar as relações entre Estados, mercados e moedas. A definição das estratégias de investimento e financiamento é feita pelos atores desse sistema no qual se incluem os Estados, a iniciativa privada, os bancos e as Instituições Financeiras Internacionais (IFIs). As duas maiores representantes das IFIs, também conhecidas como Instituições de Bretton Woods, são as que surgiram em 1944, com a Conferência de Bretton Woods, são elas: o Fundo Monetário Internacional (FMI) e o Banco Internacional de Reconstrução e Desenvolvimento (BIRD).

A concepção do SFI atual desenvolveu-se a partir da Segunda Guerra Mundial, quando foi realizado, em 1944, a Conferência de Bretton Woods, nos Estados Unidos da América (EUA). Essa conferência foi realizada com o sentido de estabilizar o SFI que se encontrava desestruturado desde a Primeira Guerra Mundial quando o antigo Padrão-Ouro ruiu. Na conferência estavam presentes 44 países não-comunistas, que vieram a discutir várias propostas para a concepção de um novo sistema financeiro, dentre as quais estavam as do economista inglês J. M. Keynes e do norte-americano Harry D. White (FOSCHETE, 2001:148).

Universitas - Relações Int., Brasília, v. 2, n.1, p. 269-288, jan./jun. 2004 
A proposta escolhida foi a do Secretário do Tesouro dos EUA, H.D. White, que previa o estabelecimento de um sistema de paridade monetária, no qual o dólar norte-americano tinha sua paridade frente ao ouro fixada em US\$ 35,00, enquanto os demais países que aderissem ao Sistema deveriam determinar seu câmbio em relação ao dólar. Para auxiliar nesse controle foi necessário criar o FMI, que visava o auxílio monetário de liquidez, para os países que passassem por déficits no balanço de pagamentos, e a supervisão do cumprimento das regras estabelecidas pelo Sistema de Bretton Woods para as finanças internacionais (SALVATORE, 2000:392-3).

O FMI serviria para manter o novo Sistema Financeiro funcionando, provendo empréstimos para os Estados conseguirem manter o novo padrão cambial adotado. Esses empréstimos eram de curto prazo, para sanar problemas específicos do balanço de pagamentos, mas em vista das dificuldades que todas as nações passavam na época da realização da Conferência, foi requisitada também a criação de um organismo que financiasse o desenvolvimento econômico. Com esse fim seria criado o Banco Internacional de Reconstrução e Desenvolvimento (BIRD), um organismo que ofereceria empréstimos de longo prazo para financiar projetos de desenvolvimento que no futuro, em conjunto com outros organismos, formariam o Grupo Banco Mundial (PILBEAM, 1992:282).

Mesmo com o fortalecimento das instituições criadas em Bretton Woods, tal sistema, como um sistema monetário, durou apenas até 1971. Apesar disso, parte do que surgiu com tal sistema continua existindo, pois, o que terminou foi apenas o padrão ouro-dólar. As duas instituições "irmãs" que dele surgiram, o FMI e o Banco Mundial, continuam em atividade. Entretanto, tais instituições precisaram sofrer algumas alterações, consideradas as mudanças pelas quais passou o SFI ao longo dos anos.

Para ROBERTS (2000:101), as IFIs assumiram novas responsabilidades após esse período. Segundo tal autor, essas instituições tornaram-se "as principais instituições públicas que operam as finanças internacionais", servindo de eixo para as relações entre os mercados financeiros internacionais. Apesar disso, ele comenta que elas estão diminuindo suas atividades em vista do

Universitas - Relações Int., Brasília, v. 2, n.1, p. 269-288, jan./jun. 2004 
aumento das atividades dos mercados financeiros internacionais que, na verdade, só estão crescendo graças à ação bem sucedida das IFIs ao longo dos anos.

O mercado financeiro também está mais ativo devido ao sistema de câmbio flutuante administrado, que o FMI tenta implementar por meio de seus empréstimos que auxiliam países com dificuldades em seus balanços de pagamentos. Mas como os déficits desse balanço cresceram muitos em vários países, suas dívidas externas também cresceram. Assim, foram estabelecidos novas políticas para empréstimos e renegociação de dívidas e o processo de negociação dentro do Sistema Financeiro Internacional tornou-se ainda mais complexo, exigindo uma atuação mais cuidadosa dos diversos atores envolvidos.

\section{O Grupo Banco Mundial}

Como foi visto acima, o Sistema Financeiro Internacional começou a se estabelecer em Bretton Woods, no ano de 1944, e dele surgiram as principais IFIs, que perduram até hoje. Para este trabalho, o Banco Mundial merece destaque por ser o primeiro e principal Banco de Fomento, ou Banco Multilateral de Desenvolvimento, existente. Segundo MAIA (1999:48) o papel dos bancos de fomento é "mediar entre os principais mercados de capitais e as necessidades de financiamento de projetos do terceiro mundo. Além disso, eles [...] proporcionam assistência técnica e assessoria na área de política econômica".

\subsection{Conhecendo o Banco Mundial}

O Banco Mundial surge com a criação do Banco Internacional de Reconstrução e Desenvolvimento (BIRD) durante a Conferência de Bretton Woods, em 1944, em resposta às necessidades de promoção da reconstrução européia no pós-guerra e o desenvolvimento das nações não desenvolvidas. Em 25 de junho de 1946, começava a funcionar o BIRD e suas primeiras ações tinham o objetivo de reconstruir a Europa. Com o estabelecimento do Plano Marshall, aos poucos esse

Universitas - Relações Int., Brasília, v. 2, n.1, p. 269-288, jan./jun. 2004 
objetivo foi deixado de lado pelo Banco. Assim, o BIRD concentrou suas atividades para o desenvolvimento econômico, em especial dos países menos desenvolvidos e em desenvolvimento (FOSCHETE, 2001:160-2).

A definição do Banco Mundial é um pouco fora do convencional, já que ele não é um banco no sentido usual da palavra. Essa dificuldade conceitual foi identificada já na época dos debates em Bretton Woods. Naquela ocasião, os delegados dos 44 países não sabiam como nomear tal instituição, mas aparentemente todos achavam adequado omitir a palavra "banco", pois o Banco tinha características mais comuns a um fundo ${ }^{4}$. O Banco Mundial não é realmente um banco, faltam a ele diversas funções ordinárias que cabem a um banco cumprir, como receber depósitos dos seus associados. O que ele faz é oferecer empréstimos a governos, ou a entidades privadas garantidas pelos governos, além disso, seus empréstimos são oferecidos a juros inferiores aos de mercado e não são direcionados a países com condições de fazer empréstimos em termos razoáveis de outras fontes (MASON \& ASHER, 1973:11-2).

Existem ocasiões em que a atuação do Banco é confundida com as do FMI, pois, em certas condições, o Banco Mundial pode oferecer Empréstimos de Ajuste, dentro de termos parecidos com os dos empréstimos do Fundo. ROBERTS (2000:102) apresenta algumas diferenças básicas entre essas duas IFI, por exemplo, o Banco Mundial é uma Instituição de Desenvolvimento que busca promover o desenvolvimento econômico nos PEDs e só faz empréstimos a esses, que normalmente são de longo-prazo, enquanto que o Fundo é uma Instituição Monetária, que faz financiamento de curto-prazo aos déficits temporários dos balanços de pagamento, emprestando a todos os seus membros. O que justificaria tal ação do Banco de empréstimos de ajuste é que PEDs com problemas nos déficits de pagamento, têm seu crescimento econômico estagnado.

De fato, o Banco passou por várias dificuldades em definir sua identidade, buscando sempre rever seus atos e redefinir estratégias e

\footnotetext{
${ }^{4}$ Interessante comentar a posição de Keynes que dizia que o Banco deveria chamar de Fundo (FMI) e o fundo deveria chamar de Banco (BIRD) (MASON \& ASHER, 1973:11).
}

Universitas - Relações Int., Brasília, v. 2, n.1, p. 269-288, jan./jun. 2004 
políticas. MASON \& ASHER (1973), por exemplo, são bem detalhistas ao descreverem os anos iniciais do Banco Mundial e os primeiros problemas que enfrentaram como instituição. $\mathrm{Na}$ época da criação do Banco havia a preocupação do grupo ser identificado com instituições financeiras mais comuns a Wall Street, ou seja, ao setor privado. Também houve a preocupação de o Banco ser confundido com um órgão assistente das Nações Unidas, mas isso foi superado e em 1947 o Banco começou seu relacionamento bem-sucedido com a ONU, sendo considerado atualmente uma agência especializada dessa Organização (BANCO MUNDIAL, 2003a).

Ainda segundo MASON \& ASHER (1973:74-79), apesar das dificuldades enfrentadas para a definição do que seria o Banco Mundial, esse não passou por grandes alterações institucionais. Os autores apresentam apenas uma exceção. Em 1952, houve uma reorganização estrutural no modo de negociação e definição dos empréstimos que visou evitar conflitos entre os funcionários do Banco sobre a responsabilidade de aprovar projetos. Essa reforma criou novos setores organizacionais mais específicos em suas funções e obrigações, tornando mais eficiente o processo de financiamento dos países.

Assim, em seu desenvolvimento institucional, o Grupo Banco Mundial foi delineando suas estruturas e políticas, de modo a assumir, atualmente, o papel de promoção ao desenvolvimento dos PEDs e PMDs por meio de financiamentos a projetos que promovam o combate à pobreza e a utilização sustentável dos recursos das nações. Entre os tipos de projetos que financia, incluem-se projetos nas áreas: de educação, saúde, agricultura, infra-estrutura, bem como praticamente todos os setores considerados sensíveis para países em desenvolvimento. Além dos auxílios oferecidos para ajustes no balanço de pagamentos, que criam a confusão entre as obrigações do Banco e as do FMI.

Atualmente, o Grupo Banco Mundial é composto de cinco agências, são elas: o Banco Internacional de Reconstrução e Desenvolvimento (BIRD), a Associação Internacional de Desenvolvimento (IDA), a Corporação Financeira Internacional (CFI), a Agência Multilateral de Garantia de Investimentos (AMGI) e o Centro Internacional para Arbitragem de Disputas sobre Investimentos

Universitas - Relações Int., Brasília, v. 2, n.1, p. 269-288, jan./jun. 2004 
(CIADI). Para realizar seus objetivos, o Grupo utiliza-se dessas agências. Cada agência possui uma atividade específica, mas normalmente o BIRD é considerado o principal representante do Banco Mundial, por ter sido a primeira agência e por administrar praticamente todos os recursos do Grupo.

As funções do BIRD, retiradas de seu Estatuto, são a de captar e oferecer empréstimos a PEDs que sejam considerados bons pagadores (WORLD BANK, 2003b). O BIRD capta seus recursos pela venda de títulos nos mercados de capitais a taxas preferenciais, de modo que possa oferecer esses recursos em empréstimos para PEDs com taxas de juros menores que as de mercado (FOSCHETE, 2001:162). GRAHAM BIRD (1989:263-4) comenta que o Banco também atrai recursos do setor privado oferecendo co-financiamento aos países, o que aumenta a disponibilidade de crédito aos PEDs.

Das outras quatro agências que compõe o Banco Mundial, vale citar ainda, por seu papel no financiamento internacional, a CFI que foi criada em 1951 com o objetivo de promover o setor privado nos PEDs por meio de empréstimo, e a IDA, criada em 1960 com o objetivo de conceder empréstimos de longo prazo, com juros muito baixos ou nulos, para projetos em países de baixa renda e com dificuldades em seus balanços de pagamentos (FOSCHETE, 2001:163-4), que normalmente se encontram entre os PMDs. O BIRD e a IDA juntos formam o que comumente é chamado de Banco Mundial, sendo a maior fonte internacional de recursos para o financiamento do desenvolvimento mundial (BANCO MUNDIAL, 2003b).

\subsection{Como trabalha o Banco Mundial}

O Banco Mundial oferece diversos serviços aos seus associados pelos quais visa realizar sua missão de erradicar a pobreza no mundo. Entre esses serviços encontram-se os estudos sobre diversos temas de desenvolvimento, consultorias para governos oferecendo know how para a adequação de políticas que visem esse desenvolvimento, além dos serviços financeiros.

Não há dúvidas quanto à importância das análises e estudos realizados pelo staff do Banco. Nesse sentido, MIKESELL (1966:61-

Universitas - Relações Int., Brasília, v. 2, n.1, p. 269-288, jan./jun. 2004 
70) comenta que desde seus primeiros anos o Banco buscou não ser apenas uma agência voltada para financiamento de projetos, tentando oferecer outros serviços que promovessem o desenvolvimento econômico.

Por exemplo, os estudos realizados pelo Banco permitem delinear suas estratégias para atingir seus objetivos desenvolvimentistas. Já seus relatórios permitem averiguar o andamento dos trabalhos e projetos realizados $\mathrm{e}$ as pesquisas estatísticas servem de base para a melhor alocação dos recursos mundiais. Tudo isso também serve de fonte para outros trabalhos, como esta monografia. Sem falar que cria o know how necessário para o estabelecimento das consultorias junto aos governos interessados, muito importantes para os PMDs que freqüentemente estão com suas instituições estatais em condições precárias e necessitam desse auxílio institucional. $^{5}$

As operações não-financeiras são também muito úteis ao Banco na definição de suas operações financeiras. Apesar das operações financeiras do Banco terem uma estrutura própria, as estratégias para a definição de empréstimos e financiamentos vêm das operações nãofinanceiras. Para saber se tais estratégias são realmente aplicadas, o melhor meio é verificar como foram utilizados os produtos e serviços financeiros do Banco.

Com esse fim, é importante saber quais são os serviços e produtos financeiros do Banco, como eles são utilizados, por quem e para o quê. Os empréstimos realizados pelo Banco são definidos segundo dois itens, os instrumentos de financiamento e os produtos financeiros. Os Instrumentos de Financiamento (ou empréstimos) são os definidores do formato do empréstimo. De acordo com o instrumento utilizado define-se como será o empréstimo e para que fins. São dois os tipos básicos de Instrumentos, os Empréstimos de Investimento e os Empréstimos de Ajuste. Os empréstimos passam por diversas fases antes de se tornarem efetivos, sendo negociados, entre o tomador do empréstimo e o Banco, os objetivos do empréstimo, sua

\footnotetext{
${ }^{5}$ MIKESELL (1966:63) também faz referências aos estudos econômicos do Banco, apesar de comentar que muitos economistas criticarem tais estudos por serem superficiais em suas recomendações.
}

Universitas - Relações Int., Brasília, v. 2, n.1, p. 269-288, jan./jun. 2004 
agenda de desembolso e pagamentos, e a viabilidade do projeto, etc. Por fim, todos os empréstimos aprovados são regidos pelas Políticas Operacionais do Banco Mundial (WORLD BANK, 2001a:3).

Os Empréstimos de Investimento são de longo prazo (de 5 a 10 anos) oferecidos pelo Banco a PEDs, ou PMDs, que se mostrem "bons devedores", para projetos que visem o desenvolvimento social e econômico. Os recursos desses empréstimos podem ser desembolsados conforme as necessidades do projeto que são direcionados, ou conforme tenha sido acordado no contrato de empréstimo. Entre os principais instrumentos utilizados por esse tipo de empréstimo, encontram-se (WORLD BANK, 2001a:6-12):

a) Specific Investment Loan (SILs), direcionados para vários tipos de projetos, mas que normalmente servem para estabelecer infra-estruturas institucionais para melhorar a utilização dos recursos financeiros em diversos setores sociais e econômicos;

b) Adaptable Program Loan (APLs), são os financiamentos padrão para o desenvolvimento de projetos e programas de longo-prazo, normalmente usado para reformas setoriais;

c) Learning and Innovation Loan (LILs), financiamento de curto prazo e que não oferece mais de US\$ 5 milhões, utilizados para testar novos modelos de projetos e verificar sua viabilidade em outras regiões; e

d) Technical Assistance Loan (TALs), esses empréstimos são para auxiliar no estabelecimento de instituições diretamente ligadas a implementação de estratégias e políticas nacionais de desenvolvimento.

Os Empréstimos de Ajuste não são voltados para projetos, a não ser quando utilizados em conjunto com os Empréstimos de Investimento, por serem oferecidos pelo Banco para um desembolso rápido (curto-prazo) por países que necessitem auxílio financeiro externo para reformas estruturais em sua economia como um todo. Os saques são feitos em estágios e segundo termos definidos pelo Banco, sendo normal a supervisão do FMI nesse processo de empréstimos para ajustes estruturais. Entre os instrumentos desse tipo de empréstimo tem-se os Structural e Sector Adjustment Loans, os

Universitas - Relações Int., Brasília, v. 2, n.1, p. 269-288, jan./jun. 2004 
Programmatic e Special Adjustment Loan, o Rehabilitation Loan e o Debt Reduction Loan (WORLD BANK, 2001a:13-9).

Quanto aos Produtos Financeiros do Banco, esses dizem respeito aos termos em que serão realizados os empréstimos e financiamentos. Apenas o BIRD se utiliza desses produtos, visto que a IDA não cobra juros ou outros encargos dos empréstimos que oferece. O BIRD dispõe de, basicamente, dois tipos de produtos financeiros, os Empréstimos de Margem Fixa (EMF) e os Empréstimos de Margem Variável (EMV). Esses dois produtos são oferecidos nas principais moedas conversíveis e suas taxas de juros são calculadas de acordo com a LIBOR $^{6}$ semestral, com a diferença de que os EMF possuem uma parte de suas taxas de juros que permanece fixa por toda a duração do empréstimo, a não ser que sejam renegociadas. Outras diferenças entre esses dois produtos incluem o fato dos EMF permitirem maior controle das taxas de juros, permitindo a negociação de correções nessas, facilitando o pagamento aos tomadores. Em compensação, os EMF incluem encargos maiores que o EMV, para compensar os riscos do mesmo (WORLD BANK, 2002a:25).

Vale citar ainda algumas linhas de crédito especiais fornecidas pelo Banco Mundial. Essas linhas referem-se a Fundos ou auxílios que não têm origem em recursos exclusivos do Grupo. Por exemplo, o Grupo Banco Mundial oferece garantias aos investidores privados que resolverem oferecer empréstimos a PEDs. Mas a maior parte das linhas de créditos se originam de outras instituições internacionais, principalmente Fundos, cuja responsabilidade de implementar seus objetivos seja do Banco Mundial (WORLD BANK, 2003c). Nesse caso, encontram-se os empréstimos oferecidos pelo Global Environmental Facility (GEF) estabelecido em 1991 e que já está envolvido em mais de 1200 projetos ambientais, inclusive no setor energético.

Com todas essas linhas de créditos, em 2002 o BIRD chegou a liberar US\$ 11,5 bilhões em novos empréstimos. CASTRO (2000:251) explica que o Banco consegue seus recursos por meio da subscrição de capital por parte de seus membros. ROBERTS (2000) comenta ainda

${ }^{6}$ LIBOR - Taxa de Oferta Interbancária de Londres.

Universitas - Relações Int., Brasília, v. 2, n.1, p. 269-288, jan./jun. 2004 
que mais recursos são captados nos mercados financeiros por meio da emissão de títulos. Desse modo, o Banco Mundial consegue tamanhos recursos para por em prática todas as suas atividades e financiar o desenvolvimento econômico e social no planeta.

\section{O Banco e o Desenvolvimento Sustentável}

A definição de Desenvolvimento Sustentável só veio a tomar forma com a publicação do relatório "Nosso Futuro Comum" pela Comissão Mundial sobre Meio Ambiente e Desenvolvimento (CMMAD) e apenas se solidificou como meta desenvolvimentista a partir da Conferência RIO-92. Mas antes disso, já existia o debate entre os defensores do meio ambiente e os defensores do desenvolvimento. No meio desse debate, encontrava-se o Banco Mundial, como uma agência de desenvolvimento que não podia ignorar o impacto do crescimento econômico sobre a natureza. A importância do Banco e de outras IFIs é tanta, que o próprio relatório do CMMAD (1991) faz questão de lembrar disso em vários momentos do livro.

Desse modo, o Banco precisou rever suas políticas de modo a considerar os problemas ambientais para o financiamento de projetos, muitas vezes em respostas às críticas dos ambientalistas. LE PRESTRE (2000:383) escreve que as primeiras críticas eram bem variadas, mas costumavam argumentar que os projetos de desenvolvimento executados com o auxílio financeiro externo eram mal elaborados, não levando em conta as questões ambientais. Assim, eles costumavam culpar as ações das instituições de desenvolvimento mais do que culpavam os PEDs.

Obviamente, o Banco Mundial não ficou indiferente às críticas dos ambientalistas, mas manteve sua perspectiva desenvolvimentista sem ignorar os problemas ambientais envolvidos. Também manteve bem focado seu objetivo de eliminação da pobreza, mas não a qualquer preço, como desejavam os ambientalistas. Assim, o posicionamento do Banco sobre como se desenvolver sustentavelmente tornou-se cada vez mais complexo. Portanto, é interessante analisar como se consolidou historicamente tal posicionamento.

Universitas - Relações Int., Brasília, v. 2, n.1, p. 269-288, jan./jun. 2004 
LE PRESTRE (2000:393-4) oferece um quadro útil a tal objetivo. O Banco sempre se preocupou com o meio ambiente, mas a partir de 1969, com a nomeação de um conselheiro sobre questões ambientais e, em 1971, com a criação do Escritório de assuntos Ambientais, tais preocupações começaram a ser institucionalizadas. Mesmo assim, na década de 1970, as críticas aos desenvolvimentistas continuaram e foram marcantes, de modo que o Banco se posicionou contra elas, rejeitando-as, como rejeitou, por exemplo, o Relatório do Clube de Roma, de 1972.

Na década de 1980, a ação do Banco no meio ambiente foi mais presente e, em 1984, foi elaborada uma primeira política global para o meio ambiente e estabelecidos os princípios para o financiamento de projetos de proteção ambiental. Em 1985, o meio ambiente é citado no relatório anual e pela primeira vez o Banco suspende um projeto por problemas ambientais. Em 1987, o Banco é reestruturado mais uma vez e foi criado o Departamento de Meio Ambiente. Dois anos depois, em 1989, foram estabelecidos os programas de assistência técnica para projetos ambientais e as políticas de estudos dos impactos ambientais. (LE PRESTRE, 2000:393).

A partir da década de 1990, as políticas e estratégias do Banco Mundial para o Meio Ambiente e o Desenvolvimento Sustentável ficam mais claras. Em 1990 foi publicado o primeiro relatório do Banco Mundial sobre o meio ambiente. Apesar do Banco já ter demonstrado sua preocupação com as questões ambientais anteriormente, esse relatório foi importante por ser um dos primeiros documentos do Banco a rever suas ações e propor a adoção de novas estratégias, buscando estabelecer uma agenda e problemas prioritários para a ação do Banco sobre o meio ambiente. Vale citar, ainda, que nesse relatório, o próprio Banco reconhece seu papel fundamental, assim como de outras agências de desenvolvimento, na assistência aos PEDs e PMDs na administração sustentável do meio ambiente (WORLD BANK, 1990).

Com a criação do GEF, em 1991, reforça-se a importância das agências de desenvolvimento na definição de estratégias sustentáveis. Segundo o relatório "Making Sustainable Commitments" (WORLD BANK, 2001b:191-8), após a Conferência RIO-92 e a fase de teste que

Universitas - Relações Int., Brasília, v. 2, n.1, p. 269-288, jan./jun. 2004 
durou até 1994, o GEF passou a ser um dos fundos mais importantes na integração de objetivos para o estabelecimento do processo de desenvolvimento global. Com sua reestruturação em 1994, esse fundo tornou-se um dos de ação mais transparente e acesso universal. Até 2001, o Banco Mundial e o GEF já haviam oferecido aproximadamente US $\$ 1,3$ bilhões em 192 projetos.

Percebe-se, assim, o aumento da conscientização do Banco em relação ao meio ambiente, apesar de uma resposta inicial negativa. $\mathrm{Na}$ última década, a importância do Desenvolvimento Sustentável para o Banco fortaleceu-se ainda mais por meio de ações como a criação da Vice-Presidência para o Desenvolvimento Ecologicamente Durável, em 1993. A evolução dessa perspectiva do Banco veio a se consolidar em 2001, com o estabelecimento de uma nova estratégia para o Desenvolvimento Sustentável e o Meio Ambiente, que é válida até hoje.

A estratégia do Banco para o meio ambiente, publicada sobre o título "Making Sustainable Commitments: An Environment Strategy for the World Bank" apresenta detalhadamente que ações devem ser tomadas a respeito do Desenvolvimento Sustentável. Trata-se de um documento bastante complexo, que revê a concepção do Banco sobre o meio ambiente, vindo a reafirmar que promover melhorias ambientais é fundamental para uma estratégia de desenvolvimento e redução da pobreza. De acordo com o documento, essa estratégia deve ser um plano de longo prazo, baseada em três metas principais: Melhoraria da Qualidade de Vida, Melhoraria da Qualidade do Crescimento e Proteção à Qualidade dos Recursos Regionais e Globais (WORLD BANK, 2001b:xx-xxii).

No relatório anual de 2002 do Departamento de Meio Ambiente do Banco Mundial, denominado "Environment Matters", é feita uma breve revisão da Estratégia do Grupo, publicada em 2001. O relatório afirma que a Estratégia Ambiental do Banco permitiu progressos em diversos setores. Por exemplo, foram iniciadas pesquisas para identificar a relação entre pobreza e meio ambiente, de modo a disponibilizar informações importantes na adoção de estratégias ambientais pelos governos nacionais, essas pesquisas,

Universitas - Relações Int., Brasília, v. 2, n.1, p. 269-288, jan./jun. 2004 
chamadas de "Poverty Reduction Strategy Papers", são utilizas principalmente pelos países beneficiados pela IDA.

Também começou a se pensar mais na análise de estratégias ambientais para cada país e região, de modo a suprir as necessidades locais de desenvolvimento sustentável, além disso, passou a ser incentivado o maior aproveitamento da assistência técnica e know how do Banco no setor ambiental por parte dos governos nacionais (WORLD BANK, 2002b:30-3). SOUZA (1999:173-88), que descreve a estratégia ambiental do Banco para o Brasil, afirma que no país as ações de assistência técnica e programas de treinamento são mais úteis e utilizadas do que os próprios financiamentos do Banco.

É interessante notar, também, a importância do meio ambiente na definição do direcionamento dos recursos de financiamento do Banco. Em 2002, de um portfólio de US\$ 100 bilhões, 14\% foram direcionados a projetos na área ambiental, contendo objetivos de controle e proteção de recursos naturais e do meio ambiente (WORLD BANK, 2002b:30-3). Normalmente esses recursos são divididos em projetos das duas agendas básicas, a "Agenda Marrom" voltada para projetos contra poluição e a "Agenda Verde", que incluem problemas como desmatamento, perda de biodiversidade, etc. (BANCO MUNDIAL, 1994:6-7). Mas ao se considerar que todos os projetos são analisados sob perspectivas sustentáveis, de modo que nenhum projeto poderia ser realizado caso ameace de alguma maneira o meio ambiente, então, teoricamente, todos os projetos são estabelecidos segundo as metas de Desenvolvimento Sustentável e todos os recursos do Banco são usados de maneira sustentável.

\subsection{Revisão crítica do trabalho do Banco}

Mesmo com todo o esforço do Banco em agir de maneira mais sustentável, diversas críticas podem ser feitas ao seu trabalho, por ter levado um bom tempo para se adaptar às novas necessidades ambientais. ROODMAN (2002:143-65) escreve sobre o problema causado ao desenvolvimento pela dívida externa e mostra que em alguns momentos da história do Banco Mundial, quando alguns países sofriam com problemas de dívida, a resposta do Banco para esses

Universitas - Relações Int., Brasília, v. 2, n.1, p. 269-288, jan./jun. 2004 
países era expandir seus empréstimos a eles. Por exemplo, os empréstimos fornecidos pelo Banco são, em sua grande maioria, de valores elevados, boa parte desses ultrapassando os US\$ 100 milhões em um projeto ${ }^{7}$. A princípio isso parece não representar problemas, mas empréstimos de valores elevados implicam em maiores serviços de dívida externa a serem pagos, deslocando recursos nacionais para fins menos sustentáveis ambientalmente.

Problemas com dívida externa obrigam, muitas vezes, os países recorrerem a novos empréstimos, os chamados empréstimos de ajustes estruturais fornecidos pelo Banco Mundial e pelo FMI. LE PRESTRE (2000:375-82) discute brevemente sobre esses empréstimos e argumenta que não existe muita certeza sobre como eles afetariam o meio ambiente, apesar de alguns ambientalistas defenderem que tais empréstimos obrigam os países a superexplorarem seus recursos naturais para saldar as dívidas adquiridas.

Já PANAYOTOU (1994:98-103) confronta tal posição ao afirmar que na medida em que são introduzidas reformas estruturais, que respeitem padrões ambientais, dentro dos termos do empréstimo, melhoras ambientais podem ser alcançadas. De qualquer maneira, a crítica de RICH (1994) é mais conclusiva, ao afirmar que mais empréstimos e financiamentos aumentam os serviços da dívida, que obrigam a se buscar mais empréstimos, criando um círculo vicioso. Os financiamentos do Banco apenas reforçam tal círculo, alocando recursos de maneira ineficiente e prejudicando o meio ambiente.

Outras críticas podem ser feitas ao Grupo e a sua atuação como um todo. SOUZA (2001:185) argumenta que o Banco Mundial entende o ambiente como um recurso econômico, de maneira que tais recursos devam ser utilizados racionalmente. Mas a racionalidade econômica nem sempre está de acordo com a "racionalidade ambiental", dessa maneira surgem contradições nas políticas adotadas pelo Banco.

Tais contradições são visíveis, por exemplo, nas tentativas do Banco de privatizar setores com condicionantes ambientais. $\mathrm{O}$ caso da

\footnotetext{
${ }^{7}$ Segundo informações coletadas no banco de dados do Grupo, disponível em: http://web.worldbank.org/WBSITE/EXTERNAL/PROJECTS/

0,,menuPK:51563 pagePK:95873 piPK:95910 theSitePK:40941,00.html. Acessado em: 15/09/2003.
}

Universitas - Relações Int., Brasília, v. 2, n.1, p. 269-288, jan./jun. 2004 
privatização do setor elétrico brasileiro, apresentado por SWITKES (2001:94-6), é característico. Ele mostra que as promessas de investimentos que existiriam no setor, caso fosse privatizado, não foram cumpridas. $\mathrm{Na}$ verdade, a privatização do setor resultou em desemprego e aumento nas tarifas, além das empresas envolvidas não demonstrarem qualquer preocupação social ou ambiental, sendo ineficiente, até o momento, o controle sobre tais empresas.

Para RICH (1994:182-99), o Banco Mundial sofre de contradições institucionais, não tendo como definir suas políticas segundo uma teoria de desenvolvimento, já que não existe uma teoria que explique tais políticas ou estratégias. Assim, descobrir como lidar com questões ambientais é um processo delicado. Apesar de Rich acreditar que se está longe do Banco ter sucesso nesse sentido, pelo visto neste artigo, percebe-se que pelo menos ele esta tentando agir segundo preceitos ambientalmente sustentáveis, atitude que nem sempre é visível em outros atores internacionais, em especial em outras IFI.

\section{Conclusão}

A criação do Banco Mundial foi uma resposta à necessidade dos países desenvolvidos de reconstruir a Europa no pós Segunda Guerra Mundial. Mas como a conferência onde se determinou a criação do Banco não envolveu apenas os países afetados pela guerra, os países mais pobres argumentaram que o Sistema Financeiro Internacional também deveria oferecer condições que promovessem o desenvolvimento de suas nações. Assim, o Banco Mundial deixou de ser uma instituição voltada para reconstrução européia, dedicando-se principalmente a promoção do desenvolvimento e eliminação da pobreza mundial.

As ações que o Banco toma para promover a redução da pobreza são as mais variadas, desde estudos políticos e econômicos até consultorias aos governos com dificuldades, além dos empréstimos de ajustes e financiamentos a projetos de desenvolvimento. No entanto, a partir da década de 1970, com o debate sobre a influência do desenvolvimento econômico sobre o meio ambiente tomando forma, o

Universitas - Relações Int., Brasília, v. 2, n.1, p. 269-288, jan./jun. 2004 
Banco mudou gradualmente suas estratégias a fim de considerar a variável ambiental em suas políticas de financiamento. Atualmente, o Banco Mundial considera que o desenvolvimento só é possível por meio da administração racional e sustentável desse meio ambiente (WORLD BANK, 2003d).

Assim, apesar das críticas, pode-se afirmar, segundo o estudado neste artigo, que o Grupo Banco Mundial passou por diversas fases em seu processo evolutivo, adotando diversas perspectivas de desenvolvimento e estratégias para atingir suas metas. Suas ações muitas vezes auxiliaram países em dificuldade, oferecendo novas oportunidades para o crescimento econômico. Atualmente, o Banco continua a promover o desenvolvimento, mas não mais nos moldes propostos na época da sua criação. Hoje, é imprescindível a consideração de aspectos ambientais na formulação de projetos desenvolvimentistas e o Grupo se propõe a seguir essa nova perspectiva.

\section{Referências Bibliográficas}

BANCO MUNDIAL. Uma Associação para o Progresso do MeioAmbiente: O Banco Mundial na América Latina e no Caribe. Washington, D.C.: Banco Mundial, 1994. . Cronologia do Banco Mundial. Disponível em:

$<$ http://www.bancomundial.org.br/index.php?action=/content/view _document\&cod_object=18 >. Acesso em: 31 de outubro de 2003a. Sobre o Banco Mundial. Disponível em: <http://www.bancomundial.org.br/index.php?action=/content/vie w_folder\&cod_object=6>. Acesso em: 31 de outubro de 2003b.

BIRD, G. International Financial Policy and Economic Development. $2^{a}$ Ed. London: Macmillan, 1989.

CASTRO, R.G. de. Relações Econômicas Internacionais. $2^{\mathrm{a}}$ Ed. Brasília: VESTCON Ed., 2000.

COMISSÃO MUNDIAL SOBRE MEIO AMBIENTE E DESENVOLVIMENTO (CMMAD). Nosso Futuro Comum. $2^{\mathrm{a}}$ Ed. Rio de Janeiro: Editora da FGV, 1991.

Universitas - Relações Int., Brasília, v. 2, n.1, p. 269-288, jan./jun. 2004 
FOSCHETE, M. Relações Econômicas Internacionais. $2^{\mathrm{a}}$ Ed. São Paulo: Edições Aduaneira LTDA., 2001.

KALECKI, M. Crescimento e Ciclo das Economias Capitalistas. $1^{\mathrm{a}}$ Ed. São Paulo: HUCITEC, 1977.

LE PRESTRE, P. Ecopolítica Internacional. $1^{\text {a }}$ Ed. São Paulo: Ed. SENAC São Paulo, 2000.

MAIA, M. E. R. Cenários para o Sistema Financeiro Internacional. Dissertação (Mestrado em Relações Internacionais) - Instituto de Ciência Política e Relações Internacionais, Universidade de Brasília. Brasília, 1999.

MASON, E.S.; ASHER, R.E. The World Bank since Bretton Woods. $1^{\mathrm{a}}$ Ed. Washington: The Brookings Institution, 1973.

MIKESELL, R.F. Public International Lending for Development. $1^{\text {a }}$ Ed. Nova Iorque: Randon House, inc., 1966.

PANAYOTOU, T. Mercados Verdes: a economia do desenvolvimento alternativo. $1^{\text {a }}$ Ed. Rio de Janeiro: Ed. Nórdica Ltda, 1994.

PILBEAM, K. International Finance. $1^{\text {a }}$ Ed. London: Macmillan, 1992.

RICH, B. Mortgaging the Earth: The World Bank, Environmental Impoverishment, and the Crisis of Development. $1^{\mathrm{a}} \mathrm{Ed}$. Boston, EUA: Beacon Press, 1994.

ROBERTS, R. Por dentro das Finanças Internacionais - guia prático dos mercados e instituições financeiras. $1^{\text {a }}$ Ed. Rio de Janeiro: Jorge Zahar Editor, 2000.

ROODMAN, D.M. Ending the Debt Crisis in: WORLDWATCH INSTITUTE. State of the World 2001. $1^{\mathrm{a}}$ Ed. Nova Iorque, EUA: W. W. Norton \& Company, 2001, p. 143-165.

SALVATORE, D. Economia Internacional. $6^{\text {a }}$ Ed. Rio de Janeiro: LTC Editora S.A., 2000.

SOUZA, H. O Grupo Banco Mundial e as estratégias de gestão ambiental global para o Brasil in: BARROS, F. (org.). As estratégias dos bancos multilaterais para o Brasil (2002-2003). $1^{\mathrm{a}}$ Ed. Brasília: Rede Brasil, 2001, p. 173-188.

SWITKES, G. Dançando no escuro: A estratégia do BID para o setor energético e sua responsabilidade pelo "apagão" in: BARROS,

Universitas - Relações Int., Brasília, v. 2, n.1, p. 269-288, jan./jun. 2004 
F. (org.). As estratégias dos bancos multilaterais para o Brasil (2002-2003). $1^{\text {a }}$ Ed. Brasília: Rede Brasil, 2001, p. 87-105.

WORLD BANK. The World Bank and he Environment - First Annual Report. Washington, D.C.: World Bank, 1990.

. World Bank Lending Instruments: Resources for Development Impact. Washington, D.C.: World Bank, 2001a. . Making Sustainable Commitments: An Environment Strategy

for the World Bank. Washington, D.C.: World Bank, 2001b. . IBRD Financial Products: Frequently Asked Questions.

Disponível em:

<http://www.worldbank.org/fps/pdf/faq ibrd fin prod.pdf $>$ (acessado em 31/10/2003). Washington, D.C.: World Bank, 2002a.

. Environment Matters 2002. Washington, D.C.: World Bank, 2002b.

Global Poverty Monitoring. Disponível em:

<http://www.worldbank.org/research/povmonitor/index.htm>

Acessado em: 03 de dezembro de 2003a.

IBRD Articles of Agreement. Disponível em:

<http://web.worldbank.org/WBSITE/EXTERNAL/EXTABOUTU S/0,,contentMDK:20049557 menuPK:58863 pagePK:43912 piP $\mathrm{K}: 44037 \sim$ theSitePK:29708,00.html>. Acessado em: 31 de outubro de 2003b.

. Product lines. Disponível em:

<http://web.worldbank.org/WBSITE/EXTERNAL/PROJECTS/0, contentMDK:20061217 menuPK:51563 pagePK:41367 piPK:51 533 theSitePK:40941,00.html>. Acessado em: 31 de outubro de 2003c.

. World Development Report 2003. Washington, D.C.: World Bank, 2003d.

Universitas - Relações Int., Brasília, v. 2, n.1, p. 269-288, jan./jun. 2004 